\title{
Fortuna crítica e influencias del escultor Iván Mestrovic en España
}

\author{
Ana ARA FERNÁNDEZ \\ Becaria Postdoctoral. Ministerio de Ciencia y Tecnología \\ Moisés BAZÁN DE HUERTA \\ Universidad de Extremadura
}

\begin{abstract}
RESUMEN. En este artículo analizamos la fortuna crítica que tuvo en España el escultor croata Iván Mestrovic, su presencia en algunas exposiciones colectivas celebradas en este país, así como la influencia que ejerció durante la primera mitad del siglo XX en escultores españoles destacados, como José Capuz, Moisés de Huerta, Victorio Macho, Juan Bautista Adsuara, Emiliano Barral, Alberto Sánchez, Joaquín Lucarini, Eulogio Blasco y Marta Gil Röesset.

Palabras clave: Mestrovic, escultura contemporánea, José Capuz, Moisés de Huerta, Victorio Macho, Juan Bautista Adsuara, Emiliano Barral, Alberto Sánchez, Joaquín Lucarini, Eulogio Blasco, Marga Gil Röesset.

ABSTRACT. We analyse in this article the critic fortune that Croatian sculptor Ivan Mestrovic had in Spain, his presence in collective exhibitions organized in this country and the influence he exercised during the first half of the XXth century on relevant Spanish sculptors as José Capuz, Moisés de Huerta, Victorio Macho, Juan Bautista Adsuara, Emiliano Barral, Alberto Sánchez, Joaquín Lucarini, Eulogio Blasco and Marta Gil Röesset.

Key words: Mestrovic, contemporary sculpture, José Capuz, Moisés de Huerta, Victorio Macho, Juan Bautista Adsuara, Emiliano Barral, Alberto Sánchez, Joaquín Lucarini, Eulogio Blasco, Marga Gil Röesset.
\end{abstract}

\section{INTRODUCCIÓN}

Demasiado celebrado hace cuarenta años, excesivamente olvidado en nuestros días ${ }^{1}$; de

1 J. PijOan y J. A. Gaya Nuño, Arte europeo de los siglos XIX y XX. Summa Artis XXIII, Madrid, 1967, pp. 479-481. Una idea que repite, años más tarde, Juan Eduardo Cirlot: "En un tiempo gozó de gran fama el serbio Ivan Mestrovic, que murió en Estados Unidos y al que se olvida en demasía hoy". J. A. CIRLOT, Arte del siglo XX, Barcelona, 1972, t. I, p. 130. este modo era presentado el escultor Ivan Mestrovic en una de las no muchas referencias emitidas sobre su obra en nuestro país, pese a haber ejercido una notable influencia en los escultores españoles en la primera mitad del siglo XX. En este artículo nos proponemos ahondar un poco más en la obra del artista croata, valorando su conocimiento en España y su presencia a través de la crítica y las exposiciones. 
Entre las marcadas influencias escultóricas que llegaban de Francia se encontraba por supuesto la de Rodin, cuya impronta puede rastrearse sobre todo en el ámbito catalán ya en el último cuarto del XIX ${ }^{2}$ y algo después en otro buen número de escultores del resto de la península ${ }^{3}$. A ellas hay que sumar la de Aristide Maillol, crucial para enmarcar el Noucentisme catalán ${ }^{4}$; así como la de Antoine Bourdelle, con su expresivo arcaísmo, mucho más próximo a nuestro autor, con el que comparte espíritu y notas estilísticas ${ }^{5}$. El belga Meunier y su heroización del mundo laboral también tuvo su parcela de protagonismo, pues no olvidemos que en 1907 se expusieron treinta y ocho obras suyas en la Exposición Internacional de Barcelona ${ }^{6}$. El expresionismo centroeuropeo de Barlach, Lehmbruck o Metzner contó quizás con una difusión más limitada ${ }^{7}$, pero tampoco era desconocido en nuestro país ${ }^{8}$.

\footnotetext{
${ }^{2}$ Ver M. DOÑATE, «Rodin i Catalunya», Rodin. Bronzes i aquarel.les del Museu Rodin de París, Barcelona, 1987, pp. 13-30.

${ }^{3}$ Sobre el tema, ver J. C. BRASAS EGIDO, «Sobre la huella de Rodin en la escultura española», Homenaje al profesor Martín González, Valladolid, 1995, pp. 295-299; VV. AA., Auguste Rodin y su relación con España, Barcelona-Zaragoza, 1996; o J. ALIX, «Rodin y la transformación de la escultura en España», Rodin y la revolución de la escultura. De Camille Claudel a Giacometti, Barcelona, 2004, pp. 26-31. Una ponencia de M. BAZÁN DE HUERTA revisaba el tema en el congreso Mateo Inurria y su tiempo, celebrado en Córdoba en 2007 y cuyas actas están próximas a publicarse en 2010.

${ }^{4}$ Una reciente exposición organizada por Caixa Catalunya retoma diversos aspectos del escultor: VV. AA., Maillol, Barcelona, 2009.

${ }^{5}$ Su figura fue difundida en España por J. DE LA ENCINA, «Figuras contemporáneas. Émile-Antonie Bourdelle», España, 1918, p. 186; o J. FRANCÉS, «Emilio Bourdelle», La Esfera, 27 de noviembre de 1919.

${ }^{6}$ El vasco Quintín de Torre es probablemente quien mejor encarna su aportación en España.

7 J. FRANCÉS reproducía imágenes de ellos en "Rodin y la escultura moderna", La Esfera, 311, 13 de diciembre de 1919.

${ }^{8}$ J. BRIHUEGA enmarca algunas de estas referencias dentro de una modernidad templada, en «A propósito de
}

El papel de Mestrovic hay que enmarcarlo junto a estas referencias, pero frente a algunos de estos autores, la deuda con su huella estilística no ha sido suficientemente reconocida.

\section{PINCELADAS BIOGRÁFICO-ESTI- LÍSTICAS}

Considerado por Rodin el más grande fenómeno entre los escultores de hoy, Ivan Mestrovic nació en 1883 en la localidad de Vrpolje (Eslovenia, Croacia) y falleció en South Bend (Estados Unidos) en $1962^{9}$. Entre 1900 y 1904 recibió una amplia formación escultórica en Viena, convirtiéndose en el escultor más representativo de la Secesión. Tras un breve periodo en Italia, se estableció en París en 1907; con motivo de la celebración del Salón de Otoño ese mismo año, conoció a Auguste Rodin, por quien siempre manifestó una gran admiración, bien patente en sus primeras obras. En 1910 se fechan las esculturas del templo de Vidovdan ("Duelo nacional”), que conmemoraban la batalla de Kosovo, y entre las que sobresalía la colosal estatua ecuestre de Marko Kraljevic. El conjunto figuró en la Exposición Internacional de Roma del siguiente año, suscitando el aplauso de la crítica artística y consiguiendo que su autor, con tan sólo veintiocho años, recibiera el Gran Premio de Escultura y, fruto de ello, un temprano reconocimiento mundial.

En estas fechas dio a conocer su obra con éxito en importantes exposiciones celebradas en Viena y Zagreb (1910), la Bienal de Venecia (1907, 1914, 1926), el Victoria

la escultura moderna en España. Entre el cambio de siglo y la eclosión de las vanguardias sobre las tres dimensiones del espacio (1900-1925)», Mateo Inurria y la escultura de su tiempo, Córdoba, 2007, pp. 22-55. También J. PÉREZ SEGURA aborda el tema en: «Inurria entre la multitud: paseos, sin guía, por la escultura contemporánea», Ibídem, pp. 56-75.

${ }^{9}$ Para conocer su biografía completa y otros aspectos, puede verse: http://www.mdc.hr/mestrovic/. 
and Albert Museum de Londres $(1915)^{10} \mathrm{y}$ en París (1919).

Hasta el comienzo de la Primera Guerra Mundial se observa un progresivo alejamiento de la estética rodiniana y cierta proximidad a la estatuaria clásica y preclásica albergada en el Museo del Louvre, el interés por la volumetría de Aristide Maillol y la monumentalidad que caracterizaba las esculturas de Antoine Bourdelle. Pero todo ello sin perjuicio de la búsqueda constante de un lenguaje personal, virado hacia la expresividad y que redundará en su época más prolífica, enmarcándose ahora algunas de sus más importantes creaciones.

Esta tendencia derivó hacia la temática religiosa durante los años de la Primera Guerra Mundial; primero con relieves en madera, para decantarse hacia 1918 por la piedra, en la que plasma también el tema de la mujer con algún instrumento musical. En el periodo de entreguerras se trasladó a vivir a Croacia, donde llevó a cabo varios proyectos, como los grandes monumentos dedicados al poeta Marko Marulic o a los obispos Gregory de Nim y Strossmayer. Otros fueron ideados para colocarse fuera de su país, caso del monumento a los indios, compuesto por dos impactantes figuras ecuestres alzadas en el Grant Park de Chicago en 1928. Previamente, en 1925, había ya mostrado sus obras en numerosas ciudades estadounidenses. Sus ansias monumentales se hacen si cabe más patentes en varios proyectos arquitecto-escultóricos, como el mausoleo de la familia Racic en Cavtat, el dedicado al soldado desconocido

${ }^{10}$ En la exposición de Ivan Mestrovic en el Victoria and Albert Museum de Londres en el verano de 1915 se mostraron setenta y cuatro de sus obras, destacando las relacionadas con el Templo de Kosovo, que fueron dispuestas en el hall central del museo. Los textos del catálogo fueron escritos por J. BONE: «Mestrovic and his art», y W. SETON-WATSON: «Mestrovic and the Jugoslav Idea». en Avala o el mausoleo de la familia Mestrovic, cerca de Otavice, donde él mismo está enterrado. En ellos la escultura queda supeditada a la arquitectura, en la que opta siempre por volúmenes de formas regulares, consiguiendo así unas composiciones de efectos muy armoniosos. Las exposiciones monográficas se suceden en los años treinta, en Zagreb, Praga, Viena, y con gran repercusión en el Jeu de Paume de París $(1933)^{11}$.

Durante los años de la Segunda Guerra Mundial, Mestrovic abandonó Yugoslavia para vivir en 1942 en Roma y desde 1943 en Suiza. En 1947 trasladó definitivamente su residencia a los Estados Unidos donde ejerció como profesor en las universidades de Siracusa y de Nôtre-Dame en South Bend, sin olvidar nunca su faceta de escultor. Se trata, sin embargo, de su etapa menos interesante temática y estilísticamente, lejana a sus imponentes producciones anteriores. Pese a ello, consiguió exponer veinticinco de sus obras en el Metropolitan Museum of Art de Nueva York en 1947, siendo la primera vez que esta institución mostraba la obra de un artista vivo. Tras su muerte, se celebraron importantes retrospectivas en el Museo Rodin de París (1969), Zagreb (1983) y Milán (1987).

El estilo de Mestrovic evolucionó desde una incipiente admiración por el arte de Rodin hacia una ambición monumentalista de connotaciones clásicas, al estilo de Maillol. Fue, sin embargo, Antoine Bourdelle a quien más se aproxima su estilo personal por la rotundidad de sus obras, la voluntad de arcaísmo y el decorativismo de

\footnotetext{
${ }^{11}$ El catálogo de la exposición en el Jeu de Paume de París en 1933 contó con una introducción de A. DEZARROIs en la que afirmaba: "Bourdelle me ha confesado, después de la muerte de Rodin, que Mestrovic era el único, fuera de las fronteras, en hacerle honor a ellos dos" (s/p). En este mismo lugar volverá a exponer de forma individual en 1955.
} 
sus acabados, especialmente en los pliegues de los ropajes con los que cubre a sus figuras. El artista francés supo dotar de fuerza a sus composiciones, convirtiéndose en un referente artístico de suma importancia en toda Europa y cuyo estilo fue en múltiples ocasiones comparado con el de Mestrovic ${ }^{12}$. Para nosotros -señalaba Gabriel García Maroto en 1920- la obra total de Bourdelle representa, en el momento actual, la afirmación más fuerte y segura de todas las expresiones plásticas. Ni Mestrovic, sabio y firme también, tiene valores tan completos; ensambla tan maravillosamente la sabiduría y la emoción; adelanta tan a justo tiempo las ricas reservas de cultura que riegan hasta lo más hondo las obras de los dos maestros $^{13}$.

Pese a estas comparaciones, Mestrovic elaboró un estilo muy personal, caracterizado por el esquematismo lineal de sus figuras, el ritmo geométrico y decorativo de los plegados y el gigantismo. Sus personajes parecen querer enmarcarse en unos volúmenes imaginarios, de ahí la representación de algunas de sus figuras en posturas bastante forzadas. Traza desnudos de una gran potencia anatómica, sinuosos en las mujeres y casi atormentados en los varones. Fuerza y carácter invaden además sus cabezas de héroes. El expresionismo es así otra nota destacada, con rasgos tan intensos que en algún momento rozan la caricatura. Y entre los recursos más extendidos y bien recibidos en la plástica hispana destacan el tratamiento geométrico de los cabellos, próximo a los modelos arcaicos y severos griegos, y las bandas estriadas curvas que ocupan prendas y fondos.

Toda su obra está marcada por una cierta vocación de trascendencia y gravedad, patente primero en los proyectos de

\footnotetext{
12 Ver C. M. LAVRILLIER y M. DUFET, Bourdelle et la critique de son temps, París, 1992.

${ }^{13}$ G. García MAROTO, «Desde París. Bourdelle en el Salón Nacional», La Esfera, 342, 24 de julio de 1920.
}

corte nacionalista y posteriormente en los asuntos religiosos. Temáticamente sus composiciones van desde las escenas con trasfondo bélico, en las que Mestrovic traduce la historia convulsa de los pueblos eslavos, hasta la ternura de una madre con su hijo; en unas y otras el escultor mantiene un deseo expreso de no dejar nunca indiferente al espectador.

\section{PRESENCIA EN ESPAÑA A TRA- VÉS DE LA CRÍTICA Y LAS EXPO- SICIONES}

Planteamos ahora una revisión, necesariamente incompleta, de las referencias sobre el escultor en los medios de difusión españoles. Las primeras noticias llegan a España a través de la prensa: entre 1915 y 1920 escritores y críticos relevantes publicaron artículos sobre el escultor en revistas nacionales y catalanas ${ }^{14}$. José Pla comenta la exposición londinense y elogia al artista, pero incluye demasiadas referencias como para encuadrarlo debidamente, al tiempo que aprovecha para arremeter contra las vanguardias cubista y futurista. Margarita Nelken, con mayor precisión y extensión, organiza sus obras en realistas, idealistas y decorativas, y las relaciona con Rodin y los secesionistas vieneses, valorando su vitalidad y verismo. El artículo de José Francés en La Esfera, intentando propiciar una exposición del artista en España, es el que tuvo mayor repercusión por su alcance nacional y el significativo número de fotografías

14 J. PLA, «Figuras contemporáneas. Ivan Mestrovic», Semanario de la vida artística, 25, 16 de julio de 1915, p. 5; M. NELKEN, «El arte balkanico. Ivan Mestrovic», Summa: revista selecta ilustrada, 4, 1 diciembre 1915, pp. 10-15; J. FRANCÉS, «Un gran escultor moderno ¿viene Mestrovic a España?», La Esfera, 248, 28 de septiembre de 1918, también recogido y completado en El año artístico 1918, Madrid, 1919, pp. 308-317. Y en Cataluña: J. ALEU, «Mestrovic el gran esculptor serbi», D'Aci D'Alla, 5, mayo 1919, pp. 448453; J. ALEU, «L'art Ivgoeslav», D'Aci D'Alla, 2, febrero 1920, pp. 140-142. 
incluidas. También fue importante el primero de los dos publicados por Joaquim Aleu en el ámbito catalán, de 1919, con nueve ilustraciones, y que recogía tanto elementos biográficos como precisas referencias al gran proyecto del Templo de Kosovo.

Que estas noticias y otras siguientes surtieron efecto nos lo prueba también un peculiar comentario del escultor gallego Francisco Asorey en una entrevista de 1930. Se refiere al final de su período madrileño y su regreso a Galicia en 1919: Por entonces todos los escultores tenían la preocupación por Rodin. Hasta los que venían de Roma tenían esa obsesión, como hoy obsesiona Mestrovic. Y como todos eran iguales y ya no podía aprender nada, me fui a Santiago ${ }^{15}$.

Igualmente surgen referencias al escultor en las revisiones generales sobre el arte de la época: Rafael Benet en 1928 lo sitúa bajo el epígrafe del Contorsionismo, e incide en sus esculturas llenas de patetismo y terriblemente estilizadas ${ }^{16}$. Mestrovic reaparece en otros textos fechados ya en los años cuarenta, con estimaciones no siempre positivas: Enrique Lafuente Ferrari, comentando la obra de Pérez Comendador, señala que es uno de los escultores en los que ya no pesa esa caligrafía modernista que arrebató a los artistas en los primeros veinticinco años del siglo, y que podemos simbolizar en una figura internacional que influyó singularmente sobre su época: Mestrovic ${ }^{17}$. El marqués de Lozoya en 1949 apunta que había conseguido contener

-

15 E. EsTÉVEZ ORTEGA, Arte gallego, Barcelona, 1930, p. 83. Recogido en R. OTERo TuÑEZ, Asorey, 25 anos depois, Cambados, 1987, p. 14.

16 A. HEILMEYER y R. BENET, La escultura moderna y contemporánea y Facetas post-rodinianas, Barcelona, 1928, p. 228.

${ }^{17}$ E. LAFUENTE FERRARI, Enrique Pérez Comendador. Esculturas y dibujos, Madrid, 1947, p. 17. R. RUFINO en 1950 cuestionaba la "dureza y falta de calidades" del croata en su texto Antonio Illanes. Escultura, Madrid, 1950, p. 55. las masas en fórmulas geométricas sin deshumanizar su arte, que conserva toda su fuerza de expresión ${ }^{18}$.

En los años cincuenta, Fernando Jiménez Placer lo cita en relación a Victorio Macho para resaltar la fusión entre la arquitectura pensada como juego de masas y la escultura como juego estructural. Juan Eduardo Cirlot, a su vez, lo enmarca junto a Minne y Hoetger en la tendencia expresionista. $Y$ en su valiosa revisión de la escultura española contemporánea en 1957, Juan Antonio Gaya Nuño relaciona el expresionismo de Mestrovic con Victorio Macho y, con acierto, ve también ecos del croata en el Monumento a los héroes de Tarragona realizado por Julio Antonio $^{19}$. Cerrando el período, en 1959 la revista Goya le dedica un artículo monográfico firmado por Ante Radaic ${ }^{20}$. Sin embargo, comprobamos cómo en la traducción al español en 1960 del estudio general de Werner Hoffman apenas se hace una pequeña referencia a nuestro escultor ${ }^{21}$.

Años después José Pijoan y de nuevo Gaya Nuño, en la Summa Artis, recuperan su figura, con un epígrafe propio y un tono muy elogioso, que valora sobre todo su versatilidad como escultor ${ }^{22}$. José MarínMedina, en su importante revisión crítica, valora el influjo del croata en artistas como Capuz y Adsuara, e incluso lo sigue consi-

\footnotetext{
18 J. CONTRERAS, MARQuÉS DE LOZOYA, Historia del arte hispánico, Barcelona, 1949, t. V, p. 618.

${ }^{19}$ F. JIMÉNEZ PLACER, Historia del arte español, Barcelona, 1955, t. II, p. 953. J. E. CIRLOT, La escultura del siglo XX, Barcelona, 1956, p. 17. J. A. GAYA NUÑO, Escultura española contemporánea, Madrid, 1957, pp. 62 y 65.

20 A. RADAIC, «Ivan Mestrovic», Goya, 31, julioagosto 1959 , pp. 20-24.

${ }^{21}$ W. HOFFMAN, La escultura del siglo XX, Barcelona, 1960, p. 72.

${ }^{22}$ Curiosamente bautizan al artista con el nombre de Juan. Op. cit., pp. 479-481.
} 
derando como una referencia válida para la escultura de postguerra ${ }^{23}$.

La evolución de la crítica y la historiografía en momentos más recientes muestra también tonos distintos. En la década de los noventa aparecía un extenso artículo de Francisco Portela Sandoval, que incluye una nota final en la que apunta brevemente algunos nombres de artistas españoles que considera influidos por Mestrovic ${ }^{24}$. Con anterioridad y en diversos momentos, Josefina Alix se ha referido al personaje, bien como referencia ${ }^{25} \mathrm{o}$ incluso con cierta animadversión ${ }^{26}$. Cabe comentar también que las citas reaparecen en bastantes introducciones a catálogos o monografías de escultores, hasta llegar a convertir a Mestrovic en una muletilla utilizada sin demasiado rigor, pues las alusiones a Rodin, Bourdelle, Maillol y otros tantos artistas se entremezclan a veces sin mucha precisión.

La otra vía a considerar es la expositiva. Si, como hemos apuntado en su perfil biográfico, Mestrovic celebró muestras monográficas en varios de los museos más importantes del mundo, España no contó con este privilegio, pese al deseo expresado por el escultor.

En septiembre de 1918, el crítico de arte José Francés escribía un artículo en la

\section{-}

${ }^{23}$ J. MARÍN-MEDINA, La escultura española contemporánea (1800-1978). Historia y evaluación crítica, Madrid, 1978, p. 193.

${ }^{24}$ F. J. PORTEla SANDOVAL, «Ivan Mestrovic», Anales de Historia del Arte, 4, 1993-1994, pp. 481-490. Aparte de los sugeridos por José Francés en Roma, remite a obras de Clará, Julio Antonio, Capuz, Planes o Soriano Montagut.

25 J. Alix TRUEBA, Escultura española 1900-1936, Madrid, Ministerio de Cultura, 1986. Lo cita en relación a Macho, Capuz, Adsuara o Asorey.

${ }^{26}$ En Francisco Pérez Mateo. Escultor. 1903-1936, Madrid, 2002, p. 20, señala, hablando del los años 1925-30: “...negándose a seguir el camino del viejo clasicismo, o del chirriante expresionismo del croata Mestrovic, inexplicablemente de moda y seguido por multitud de sus contemporáneos". revista La Esfera dirigido al por entonces Director General de Bellas Artes, el escultor Mariano Benlliure; en él expresaba el deseo del propio Mestrovic, quien por entonces residía en Roma, de llevar a cabo una exposición monográfica en la capital española ${ }^{27}$. Una solicitud que, según su opinión, debía tomarse en consideración al calificarlo, en este mismo texto, como el más admirable de los escultores contemporáneos.

Mariano Benlliure respondió con prontitud y personalmente a la petición en esta misma revista, apuntando la dificultad que suponía la recaudación del presupuesto económico necesario para llevar a cabo exposiciones de esta índole y, con cierto tono propagandístico, daba a conocer las dos muestras que él mismo había programado para el siguiente año: una de Arte francés en Madrid y otra de Arte español en París $^{28}$. Pese a ello, decía conocer la obra de este genio de la raza eslava, considerando muy oportuna la celebración futura de dicha exposición, aunque el proyecto no vería finalmente la luz.

Desaprovechada esta gran oportunidad, debemos esperar al mes de agosto de 1929 para poder contemplar en la Exposición Internacional de Barcelona cinco de sus esculturas, entre las que sobresalen el mármol blanco "Contemplación", el bronce "La bailarina" y el relieve en granito negro "Mado$n a^{\prime 29}$; Contemplación obtuvo la medalla de oro $^{30}$. Del dinero que dispuso el estado para

\footnotetext{
${ }^{27}$ J. FRANCÉS, «Un gran escultor moderno ¿viene Mestrovic a España?», La Esfera, 248, 28 de septiembre de 1918. Francés recogía en realidad una petición transmitida por Jesús María Perdigón, escultor por cierto que revela ecos de Mestrovic en su Madonna presentada a la Exposición Nacional de 1926.

${ }^{28}$ M. BENLLIURE, «La exposición Mestrovic en España», La Esfera, 250, 12 de octubre de 1918.

${ }^{29}$ FORTUNIO, «La exposición de Barcelona. Las secciones extranjeras en el Palacio de Arte Moderno», La Esfera, 814, 10 de agosto de 1929, p. 46.

${ }^{30}$ Información sobre el pabellón yugoslavo con la
} 
la adquisición de obras de autores extranjeros, casi la mitad se empleó en comprar el bronce de Mestrovic, por R. O. de 11 de febrero de 1930, para el Museo Nacional de Arte Moderno de Madrid, incorporándose así a nuestras colecciones. Pasó en 1968 al Museo Español de Arte Contemporáneo en Madrid, y fue cedido en 1975 al Museo de Arte Contemporáneo de Toledo ${ }^{31}{ }^{32}$.

Años más tarde, en octubre de 1953, el parque del Retiro madrileño fue el escenario para la celebración de una Exposición Internacional de Escultura ${ }^{33}$ en la que destacaron las piezas presentadas por los artistas italianos y la Jovencilla de Ivan Mestrovic; una escultura fechada en 1924 en realidad poco representativa de su estilo. La crítica se hacía eco de la presencia de este artista, y si para Figuerola-Ferreti, la representación extranjera es parca para nuestra sed de conocimiento directo. Lo de Mestrovic no es pieza de excepción en su haber ${ }^{34}$, para Gaya

reproducción fotográfica de la obra la encontramos en M. ROMANI, «El Reino de Yugoslavia», Exposición Internacional de Barcelona, Diario Oficial, 33, 19 de octubre de 1929 (sin paginar). También lo recoge B. DE PANTORBA, Historia y crítica de las Exposiciones Nacionales de Bellas Artes celebradas en España, Madrid, 1980, pp. 278-282.

${ }^{31}$ Catálogo del Museo de Arte Contemporáneo de Toledo, Madrid, 1975, pp. 171-173. La obra aparece citada con el título de Contemplación.

${ }^{32}$ En el catálogo de la exposición antológica celebrada en Milán en 1987 se cita una exposición de Mestrovic en Valencia en 1930, junto a su esposa Ruza Mestrovic, extremo que no se corrobora por otros medios; pensamos pues que se trata de un error. M. GEROSA, «Cronología», Ivan Mestrovic, Milán, 1987, p. 28.

${ }^{33}$ Sobre esta exposición de escultura al aire libre celebrada en Madrid, ver A. ARA FERNÁNDEZ, "Una experiencia inédita en España: las exposiciones de escultura al aire libre", Espacio, Tiempo y Forma, serie VII, t. 17, 2004, pp. 239-262.

${ }^{34}$ L. FIGUEROLA-FERRETI, «Primera exposición internacional de escultura al aire libre», Arriba, 11 de noviembre de 1953, p. 23.
Nuño, una gloriosa obra de Ivan Mestrovic era lo mejor del conjunto ${ }^{35}$.

Al margen de estas obras expuestas en nuestro país, los escultores españoles tuvieron la oportunidad de contemplar directamente su arte en varias ocasiones, entre las que destacamos, por su importancia, la exposición celebrada en Roma en 1911 y en París en 1919.

En la Exposición Internacional de Roma, Mestrovic estuvo representado en el pabellón serbio con los relieves y las figuras del templo de Kosovo, un amplio conjunto, exaltado y monumental, que tuvo una enorme repercusión. Destacaban la estatua ecuestre de Marko Kraljevic, las cariátides, la esfinge, la viuda con el huérfano en sus brazos, las cabezas de los héroes, las dos viudas y las figuras de los esclavos; también uno de los retratos de su propia madre y las obras Inocencia, Milos Obilic o Recuerdo. En Roma estaban entonces José Capuz y Moisés de Huerta, pensionados en la Academia Española, aunque según el crítico José Francés, fueron varios los escultores españoles que pudieron contemplar estas obras, sintiéndose atacados luego de un mestrovicismo absurdo, teniendo en cuenta las enormes diferencias étnicas que del maestro eslavo nos separan ${ }^{36}$.

En 1919, coincidiendo con la exposición antes mencionada de Arte español en París, tenía lugar en el Petit Palais de la capital francesa una exposición de artistas yugoslavos en la que sobresalía la obra de Iván Mestrovic. Los artistas españoles allí representados fueron el propio Mariano Benlliure, José Llimona, Mateo Inurria, Victorio Macho, Quintín de Torre, Moisés

\footnotetext{
35 J. A. GAYA NuÑO, «Arte. Crítica de exposiciones», Ínsula: revista biográfica de Ciencias y Letras, 96, 15 de diciembre de 1953, p. 8.

${ }^{36}$ J. FRANCÉS, «Un gran escultor moderno ¿viene Mestrovic a España?», op. cit.
} 
de Huerta y José Clará, entre otros ${ }^{37}$. Benlliure sí acudiría como organizador de la muestra, y del resto al menos pudo coincidir en la capital francesa Victorio Macho, que viajó a París ese año para estudiar la posibilidad no cumplida de instalarse allí ${ }^{38}$.

\section{SU INFLUENCIA EN ALGUNOS ESCULTORES ESPAÑOLES}

Si escasa e insuficiente fue la presencia de las obras de Ivan Mestrovic en España, esta afirmación no se corresponde con la influencia ejercida en los escultores españoles en la primera mitad del siglo XX. Las fotografías de sus creaciones mostradas en numerosas revistas españolas y extranjeras a las que pudieron tener acceso nuestros artistas podían resultar suficientes para asimilar su estilo y la fuerza de sus propuestas. Las próximas notas irán situando en el tiempo cómo marcó a diversos artistas en una primera fase, pero su figura no sería olvidada en momentos posteriores.

El grupo de escultores seleccionados incluye nombres significativos, y otros menos conocidos, pero también interesantes. Cada uno supo adecuar el personal estilo del artista eslavo a sus propios intereses artísticos.

En los dos primeros confluyeron circunstancias similares y es en Italia donde contactaron directamente con la obra del croata. El valenciano José Capuz (18841964) estuvo pensionado en Roma desde 1906; en abril de 1911, año en el que contrajo matrimonio en la capital italiana, se sintió fuertemente impactado tras visitar la Exposición Internacional. Sumó así la impronta de Mestrovic a la admiración en su fase formativa por Miguel Ángel, Rodin o Meu-

-

37 J. FRANCÉS, «La exposición española en París», La Esfera, 281, 17 de mayo de 1919.

${ }^{38}$ J. CARROBLES, «Apuntes biográficos de un artista itinerante», Victorio Macho. La mirada, Palencia, 2003, pp. 63-66. nier. No es extraño pues que en su obra más importante de ese periodo, el gigantesco grupo Paolo y Francesca de Rimini (Primera Medalla en la Exposición Nacional de 1912), fusione ya la influencia rodiniana dominante con notas propias de Mestrovic en el tratamiento de los cabellos, similares a sus cabezas de héroes.

Más claro en su ascendencia es el altorrelieve El ídolo, que Capuz presentó en la Exposición Nacional de 1922. Es una enigmática composición, de resonancias orientales, que protagoniza una figura sedente con las piernas cruzadas ante un fondo en el que se despliegan diagonalmente unas marcadas ondulaciones. Participa también de ese aire trascendente y solemne que envuelve las producciones del croata ${ }^{39}$.

Su influencia se hace también evidente en los relieves y esculturas destinadas a la arquitectura, que, en palabras del crítico Ramón Pulido, vuelven la vista a esas épocas lejanas en que la escultura se nutría de la arquitectura para, unida a ella, formar un conjunto armónico en todas sus partes ${ }^{40}$. Lo vemos en los relieves y la figura de la Justicia para el Círculo de Bellas Artes de Madrid en el edificio de La Equitativa, de una gran rotundidad compositiva. Aprovechamos esta referencia para comentar que el proyecto para el nuevo edificio del Círculo en 1920 preveía incluir, aunque finalmente no se instaló, un elocuente grupo escultórico,

${ }^{39}$ La similitud fue ya señalada por J. MARÍNMEDINA, op. cit., p. 125.

${ }^{40}$ R. PUlido, «José Capuz», La Correspondencia de España y del Extranjero, 19 de junio de 1925. Este mismo crítico reiteró en varias ocasiones la influencia que sobre Capuz realizó Mestrovic; así sobre una obra posterior de la década de 1950, Saliendo del baño, comentaba Ramón Pulido al hacer la crítica de la Exposición de Artistas Ibéricos: “José Capuz es discípulo fervoroso de Mestrovic, y esto le honra, porque el escultor servio es grandioso, sereno y escultural en grado sumo". Recogido en VV. AA., La Sociedad de Artistas Ibéricos y el arte español de 1925, Madrid, 1995, p. 291. 
titulado Pegasos, símbolos del Genio y del Ideal, concebido por Ángel García Díaz, y cuyo modelo, en el tratamiento de la musculatura y detalles como las alas y la cola de los caballos, muestra igualmente una clara relación con Mestrovic ${ }^{41}$.

Volviendo a Capuz, podemos encontrar también paralelismos en alguna de sus maternidades, pero cabe consignar que la crítica no siempre vio con admiración la deuda estilística establecida con el artista croata. Así, José Francés, sobre la sección de escultura de la Exposición Nacional de 1920 $\mathrm{y}$ en referencia a dos obras de Inurria y Clará señalaba: Ninguna de ellas conduce a aquel absurdo mestrovicismo -en pugna con todas las características españolas- importado por el Sr. Capuz como una lamentable adherencia de su periodo de pensión en Roma. Sobre algún que otro artista todavía no salido del anonimato o condenado ya a volver a él, esta Exposición señala ya el olvido del mestrovicismo... a través del capucismo ${ }^{42}$. Con todo, la obra del valenciano obtuvo a lo largo de su trayectoria múltiples elogios, dentro y fuera de esta línea ${ }^{43}$.

Como él mismo se definía, el castellano montado en vasco Moisés de Huerta (1881-1962) disfrutó su pensionado en la Academia Española de Roma entre 1909 y 1914. Durante esa etapa afianzó su clasicismo, pero sobre todo desarrolló, como Capuz, una temprana influencia rodiniana, que demuestran celebradas creaciones como Hetaira o El salto de Léucade (Primera medalla compartida con Capuz en la Nacional de 1912 y hoy en el Círculo de Bellas

\footnotetext{
${ }^{41}$ Ver J. L. TEMES, El Círculo de Bellas Artes. Madrid, 1880-1936, Madrid, 2000, p. 301.

42 J. FRANCÉS, «La Exposición Nacional. La escultura», La Esfera, 335, 5 de junio de 1920, s/p.

${ }^{43}$ Ver F. DiCENTA DE VERA, El escultor José Capuz Mamano, Valencia, 1957, pp. 69-80.
}

Artes de Madrid $)^{44}$. Huerta participó en la Exposición Internacional de 1911, siendo uno de los protagonistas de la intensa polémica suscitada en torno al pabellón español, recogida de forma pormenorizada en estudios previos ${ }^{45}$. Pudo así conocer directamente el gran conjunto escultórico desplegado por Mestrovic en el pabellón serbio, y la consecuencia inmediata se percibe en una de las obras más destacadas de su periodo italiano: Naturaleza. Es un altorrelieve de gran formato, gestado en $1911 \mathrm{y}$ compuesto por dos vigorosos desnudos. En su figura masculina confluyen la potencia anatómica del Torso Bellvedere y la escultura miguelangelesca, pero también algunos de los altorrelieves plasmados por Mestrovic en los paneles del Templo de Kosovo. Aún más clara es la filiación de su desnudo femenino, que remite al mármol $R i$ cordanza y cómo no al entronque común con La Noche de Miguel Ángel.

José Francés también comentó las influencias en Huerta, y con motivo de su triunfo en la Exposición de Pensionados de 1914, señaló: Claro es que hay sobre todas las esculturas presentadas las sombras de Rodin y Mestrovic, pero ese mal endémico de los jóvenes escultores españoles es casi un bien cuando se manifiesta en artistas como Moisés de Huerta, por ejemplo ${ }^{46}$. Aunque ahora de forma matizada, en el texto se perciben de nuevo las reticencias de Francés, basadas en la idea de que el espíritu de Mestrovic no es afín al español y no hay porqué intentar emularlo,

\footnotetext{
${ }^{44}$ Ver M. BAZÁn DE HuERTA, El escultor Moisés de Huerta. 1881-1962, Bilbao, 1992.

${ }^{45}$ Ver M. BAZÁN DE HUERTA, «La Exposición Internacional de 1911 en Roma y el arte español», NorbaArte VIII (1988), 1989, pp. 231-250; A. ARA FERNÁNDEZ y E. QUERCI, «Roma 1911: Presencia y fortuna crítica del arte español», Goya, nº 329, 2009, pp. 342-351.

${ }^{46}$ J. FRANCÉS, «Nuestros artistas en Roma. La exposición de los pensionados», La Esfera, 23, 6 de junio de 1914.
} 
pero es evidente que supo valorar las condiciones plásticas del eslavo.

La valoración de la trayectoria del palentino Victorio Macho (1887-1966) se ha revelado con el tiempo de una gran complejidad. Tras el amplio estudio de José Carlos Brasas $^{47}$, otras aproximaciones han ido aportando nuevos parámetros con los que enmarcar su obra, como puso de manifiesto en fechas relativamente recientes la exposición La mirada ${ }^{48}$. El primero apuntaba cómo tras un primer interés por la obra de Rodin, a partir de sus viajes por Italia y Francia, mostró su admiración por la obra de Bourdelle y Mestrovic, a los que debería la robustez de sus formas, la rotundidad de los volúmenes construidos a base de amplios planos y la eliminación del detallismo superfluo, sin descartar la valoración de la masa y las formas netas de un Maillol.

Este cúmulo de referencias contrasta con la visión previa de otras notas críticas, como la de José Camón Aznar, que en 1975 y en aras de reivindicar la clara españolidad del escultor, señalaba: No tienen sus esculturas las pedantescas estilizaciones de un Mestrovic, con el que presenta, por otra parte, alguna semejanza, ni el énfasis de Bourdelle, ni la grosura esquemática de un Maillol $^{49}$. El propio Macho tuvo una actitud algo ambivalente en estos reconocimientos ${ }^{50}$, pero en concreto las deudas con el escultor croata pueden

47 J. C. BRASAS EGIDO, Victorio Macho. Vida, arte y obra, Palencia, 1987.

${ }^{48}$ Destacamos sobre todo el estudio de J. BRIHUEGA, «Presencias de Victorio Macho. Apuntes para una relectura razonada», en Victorio Macho. La mirada, op. cit., pp. 93-110, quien revisa con agudeza los estudios previos y abre nuevos y sugerentes enfoques.

49 J. CAMÓN AZNAR, «Sobre las Memorias de Victorio Macho», Goya, 125, marzo-abril de 1975, p. 305.

50 En su libro Memorias, Victorio Macho únicamente reconoce la influencia que sobre él ejerció la figura de Antoine Bourdelle. Años antes, en los tres diálogos imaginarios que fueron escritos por J. DE LA ENCINA, Monografía de Victorio Macho, Madrid, 1926, sí que aparece en varias ocasiones citado Ivan Mestrovic. rastrearse en diversos momentos de su producción.

$\mathrm{Su}$ influencia se ha querido ver ya en trabajos tempranos ${ }^{51}$, y en monumentos como el de Benito Pérez Galdós de 1918 para el parque del Retiro, donde practica una escultura-bloque en que no tiene cabida el hueco. También se han establecido paralelismos entre las esculturas dedicadas a sus madres por sendos $\operatorname{artistas}^{52}$; en ambas se percibe el interés por la solidez de la estatuaria egipcia, que el croata traslada además a otras creaciones, emulando la postura sedente de los escribas o el concepto de estatua-cubo ${ }^{53}$. Más matizada es la filiación en otros casos; en concreto en la fusión tan singular entre escultura y geometría que Macho lleva a cabo en obras como la estatua yacente de su hermano Marcelo (1920), el sepulcro de Tomás Morales (1922) o en su Cristo del Otero (1930). Es cierto que parte de la producción de Mestrovic se vincula a marcos arquitectónicos, pero su forma de relacionar ambos elementos no coincide tanto con la solidez constructiva y el esquematismo volumétrico del palentino.

Junto a este modo de trabajar el bloque escultórico, Macho aporta el decorativismo en la manera de representar los plegados de los ropajes o en los cabellos, mediante la disposición de líneas paralelas, rectas o curvas, que aportan dinamismo a su estructura; una característica muy mes-

\footnotetext{
${ }^{51}$ Para Josefina Alix, fue a partir del sepulcro del Dr. Llorente en 1917 cuando se comenzó a percibir "un cierto monumentalismo, tendente a la exageración, muy influido por el expresionismo épico y teatral del tan aclamado Ivan Mestrovic". J. ALIX, «Los protagonistas. Victorio Macho», Un nuevo ideal figurativo. Escultura en España 1900-1936, Madrid, 2001, p. 310.

${ }^{52}$ Así lo hace F. PORTEla SANDOVAL, Historia del Arte Hispánico. VI. El siglo XX, Madrid, 1980, p. 148.

53 Perceptible con claridad en piezas como Contemplación (1923), La historia de los croatas (1932) o Mujer doliente (1953).
} 
trovicista, que se percibe en la Victoria alada que el palentino concibe para el monumento a Juan Sebastián Elcano en su localidad natal de Guetaria $(1925)^{54}$. De resonancias clásicas sólo en su concepto, pues emula a la Victoria de Samotracia, se asocia con el nombre del barco del descubridor, y la vinculación con el mar se refleja además en la transición multidireccional de pliegues y olas. Unas soluciones geometrizantes y expresivas similares se aprecian también en el monumento al almirante Grau en Lima (1940-1946) y en el proyecto de estatua ecuestre a Simón Bolívar (1945-1948), ya en fechas bastante avanzadas.

Por otro lado, en los relieves de estos monumentos y otros anteriores observamos asimismo similitudes entre ambos artistas, por su carácter arcaizante y simplicidad geométrica. Así ocurre con Fons vitae y Fons mortis, situados en el muro del monumento a Santiago Ramón y Cajal en el Retiro madrileño (1922), o en las Provincias de Panamá que decoran el monumento a Belisario Porras en esta misma ciudad (1944-1948).

Otro de los escultores analizados, Juan Bautista Adsuara (1893-1973), siguió la línea estilística trazada por Victorio Macho $\mathrm{y}$, de igual modo, se sintió fuertemente atraído por el arte de Mestrovic ${ }^{55}$. De ellos toma el gusto por la geometrización y el predominio de la recta sobre la curva, aunque conserve también un cierto toque académico. En los años veinte Adsuara viajó por Francia, Italia y Alemania, y tuvo contacto con algunos aspectos de la vanguardia europea. Como él mismo explicaba, sus obras, al igual que toda la escultura que se

\footnotetext{
${ }^{54}$ La versión en pequeño tamaño y en bronce de esta obra fue expuesta en la exposición de los Ibéricos de 1925. Ver La Sociedad de Artistas Ibéricos y el Arte Español de 1925, op. cit.

55 J. MARÍN-MEDINA apunta esta doble admiración en op. cit., p. 127; y lo reiteran J. A. BLASCO CARRASCOSa y F. Agramunt LaCruZ, Arte valenciano. Años 30, Valencia, 1998.
}

estaba realizando en su época, surgían como reacción contra los elementos del pasado impresionista ${ }^{56}$, de ahí su empleo de volúmenes de apariencia cubista y la economía de medios con que abordó sus grupos escultóricos.

Al igual que en Macho, las influencias de Mestrovic se hacen más evidentes en relieves y esculturas aplicadas a la arquitectura, caso de la decoración exterior del Círculo de Bellas Artes y de los relieves de la antigua sede del Banco Bilbao Vizcaya, que realiza junto a José Capuz en Madrid. Pero sobre todo se manifiestan en las Alegorías de El Arte y La Ciencia que esculpe en 1929 para la fachada del Ministerio de Educación y Ciencia en Madrid. Por ellas fue galardonado con el Premio Nacional de Escultura de ese mismo año. Su configuración corpórea remite a un neocubismo que sólo parcialmente se percibe en el croata, pero los rostros de estas singulares figuras son perfectamente equiparables a las cabezas de héroes que tanto caracterizaron al eslavo, presentándose ahora con un sintetismo ligeramente más aristado.

Aún hay otro aspecto en el que pueden encontrarse paralelismos. Las maternidades fueron una constante en la obra de Adsuara en los años veinte y cuarenta, y también un tema muy querido para Mestrovic $^{57}$. En pie, sedentes o en actitud recogida, reflejan similares soluciones formales, a su vez próximas a las halladas por Capuz.

Más joven que los citados, el escultor alavés Joaquín Lucarini (1905-1969) también recibe la influencia mestrovicista. En-

\footnotetext{
${ }^{56}$ F. CABEZA, «Juan Bautista Adsuara», La Gaceta Literaria, 15 de octubre de 1929, p. 3.

${ }^{57}$ Ya lo percibió Javier Pérez Rojas, quien al comentar la escultura de la madre con pañuelo de campesina apuntaba "una sensibilidad muy mediterránea, recordando en ocasiones una influencia del entonces muy admirado Mestrovic". F. J. PÉREZ RoJAs, Tipos y Paisajes 1890-1930, Valencia, 1998, pp. 252-253.
} 
tre 1929 y 1931 residió en París y en Bruselas y viajó por Italia, asimilando diversas tendencias. Hay una pieza en concreto que supone una traslación bastante directa de sus pautas. En 1930 Mestrovic instaló en Belgrado el Monumento de gratitud a Francia por su ayuda durante la Primera Guerra Mundial. En su pedestal introduce algunos relieves alusivos, pero nos interesa la espectacular imagen femenina que corona el monumento. Es una corpulenta mujer en forzada torsión, que eleva y proyecta sus brazos hacia atrás; su torso se muestra desnudo, pero en realidad viste una túnica cuyos pliegues, fuertemente geometrizados, corren paralelos en la misma dirección.

Pues bien, en 1932 Lucarini presentaba en la Exposición Nacional de Bellas Artes La Victoria de la Música, obra de gran formato en yeso por la que obtuvo una bolsa de estudio. Los paralelismos resultan evidentes, aunque puedan detectarse variaciones. La iconografía de esta obra es la de una Niké, y apunta unas breves alas, pero la disposición y el juego de pliegues reflejan su deuda con el croata, al igual que con cierto espíritu Art Déco ${ }^{58}$.

Eulogio Blasco López (1890-1960) fue un polifacético artista cacereño, que además de escultor trabajó como repujador, pintor y dibujante ${ }^{59}$. Tuvo menor proyección que los antes reseñados, pero asumió de forma intensa la influencia de Mestrovic. Se formó en Madrid, y por su condición de sordomudo estuvo vinculado a los hermanos Zubiaurre y el pintor inglés $\mathrm{O}^{\prime}$ Neale. Tuvo una amplia actividad artística en la segun-

\footnotetext{
58 Aunque ninguno percibe la vinculación con Mestrovic, ver, sobre el artista: A. DE BEGOÑA y M. J. BERIAIN, Joaquín Lucarini, escultor, Vitoria, 1985; y M. A. MARRODÁN, «Vida, obra y arte escultórico de Joaquín Lucarini», en Eusko-Ikaskuntza. Sociedad de Estudios Vascos. Artes plásticas y monumentales, 5, 1988, pp. 279344 .

${ }^{59}$ Ver M. BAZÁn DE Huerta, Eulogio Blasco. Cáceres, 1890-1960. Cáceres, 1991.
}

da y tercera década del siglo XX, y en 1929 y 1930 viajó por buena parte de Europa. Dato relevante para nuestro tema es que culminó un prolongado viaje por Italia con una estancia en Zagreb, donde pudo conocer directamente obras del escultor eslavo. Asentado en Cáceres desde 1935, se dedicó a la docencia y su producción disminuyó un tanto en creatividad. Su primera etapa madrileña fue por tanto la más interesante, y mereció los elogios de José Francés y otros críticos $^{60}$. Desarrolló un lenguaje de marcado acento simbolista, poblado por alegorías de las artes con formas globulares, toros totémicos de acusada volumetría y personajes oferentes o reflexivos en actitud trascendente. Huellas de Mestrovic se perciben en las enigmáticas ilustraciones para el libro de José de Hinjos (Tomás Morales) Sugestiones. Beethoven, de 1927, pero también en pinturas, esculturas y relieves que protagonizan máscaras, contorsiones y sinuosos elementos decorativos que agrupa bajo el título de Fantasías.

En esta revisión queremos introducir también a la malograda escultora e ilustradora Marga Gil Röesset (1908-1932), joven madrileña de corta producción y corta vi$\mathrm{da}^{61}$. Su trágica historia personal ha mediatizado la valoración de su obra escultórica, que a pesar de su juventud ofrece un alto nivel de calidad ${ }^{62}$. De formación autodidac-

${ }^{60}$ S. LAGO (José Francés), «La vida artística. Tres escultores jóvenes», La Esfera, II, 84, 15 de agosto de 1915. Diez años después volvería a ocuparse del artista: «El repujador Eulogio Blasco», El año artístico 1924, Madrid, Mundo Latino, 1925, p. 342. J. BLANCO CORIS, «Arte y artistas. Exposición Eulogio Blasco López», Heraldo de Madrid, 21 de abril de 1920. L. GIL FILLOL, «Arte y artistas. Esculturas y repujados», La Tribuna, abril de 1920. CORREA CALDERÓN, La ilustración Española y Americana, julio de 1920.

${ }^{61}$ Se suicidó a los 24 años ante la inviabilidad de su amor por el poeta Juan Ramón Jiménez.

62 José Francés ya se ocupó de ella en sus inicios escultóricos y tras su muerte. J. FRANCÉS, «Marga Gil Röesset», La Esfera, 17 de agosto de 1929; IDEM, «La semana artística», Nuevo Mundo, XXXIX, 2008, 2 de 
ta, pero amplia de miras en lo cultural, sorprendió en la Exposición Nacional de 1930 con la presentación de su grupo Adán y Eva. Es probablemente uno de los ejemplos más duros y singulares del expresionismo español, sustentado además por un planteamiento convincente ${ }^{63}$. Su concepción entronca con Mestrovic y corre también pareja a otros representantes del expresionismo centroeuropeo. Aunque su personal visión del mundo infantil la guió por otros derroteros temáticos, con La mujer del ahorcado, de 1932, alcanzó de nuevo altas cotas de fuerza y dramatismo.

\section{IDEAS FINALES}

Así, y por lo visto hasta este momento, la obra de Ivan Mestrovic, el Miguel Ángel yugoslavo ${ }^{64}$, alcanzó una considerable repercusión en el devenir de la escultura figurativa en la primera mitad del siglo $X X$ por tierras europeas y también en España. En parte por encarnar una vía expresionista que se reveló como alternativa válida a las propuestas clásicas o rodinianas; también por su adecuación posterior a la estética propia del Art Déco ${ }^{65}$, e incluso por su habilidad para conseguir que su orgullo patrió-

septiembre de 1932. Con posterioridad, una exposición en Madrid ha recuperado su figura para el panorama artístico. VV. AA., Marga Gil Röesset 1908-1932, Madrid, 2000. Ver también la página de A. SERRANO VELASCO: http://perso.wanadoo.es/margaroesset/.

63 En una entrevista describía el grupo como “Adán y Eva, padres del género humano, viejos como el mundo. Atlético él, fuerte como para engendrar a todos los hombres. Débil ella, apoyada en el robusto pecho del hombre, pero amplio su seno como para amamantar a toda la Humanidad. En sus caras reflejado el dolor, dolor del paraíso perdido, dolor de sentirse solos en medio del planeta, dolor por todos los dolores que habrán de arrastrar sus hijos a través de los siglos". R. ARCINIEGA DE GRANDA, "Las mujeres en la Exposición Nacional de Bellas Artes", Crónica, 19 de junio de 1930.

${ }^{64} \mathrm{~J}$. RUDEL, L'art et le monde moderne, t. 1, París, 1970, p. 305. 1990.

${ }^{65}$ Ver J. PÉREZ ROJAS, Art Déco en España, Madrid, tico y sus mensajes políticos trascendieran el ámbito particular para formar parte de un lenguaje universal.

Continuador de Bourdelle, ambos supieron incorporar a su sentido sintético y arquitectónico de las formas una concepción arcaizante y una severidad helénica que mezclaron con ciertas simplificaciones cubistas. Fue precisamente este esquematismo de gusto arcaico y decorativo el que con más fuerza caló entre los escultores españoles mencionados y en otros tantos que, en algún momento de su carrera artística, coquetearon con estas premisas estéticas, como Julio Antonio (1889-1919), Emiliano Barral (1896-1936) ${ }^{66}$ o incluso, en coordenadas bien distintas, el mismo Alberto Sánchez ${ }^{67}$.

\footnotetext{
${ }^{66}$ Véanse las geométricas figuras dolientes para sendos panteones en Segovia y Agreda, de 1925, o los relieves para el monumento a Pablo Iglesias en 1930. J. M. SANTAMARíA, Emiliano Barral, Segovia, 1985, p. 83, reeditado por la Junta de Castilla y León en 1986, pp. 77-78.

${ }^{67}$ A. Gómez CeDillo apuntaba ya en su Tesis Doctoral de 1992, La escultura de Alberto Sánchez, p. 107, la posible inspiración del Guerrero del siglo XII (conocido también como El Cid a caballo) en el Marko Kraljevic de Mestrovic. Cit. por J. BRIHUEGA, “Una estrella en el camino del arte español", Alberto 1895-1962, Madrid, 2001, p. 32. Alcaén, el hijo de Alberto, confirmaba la admiración de su padre por el escultor croata.
} 


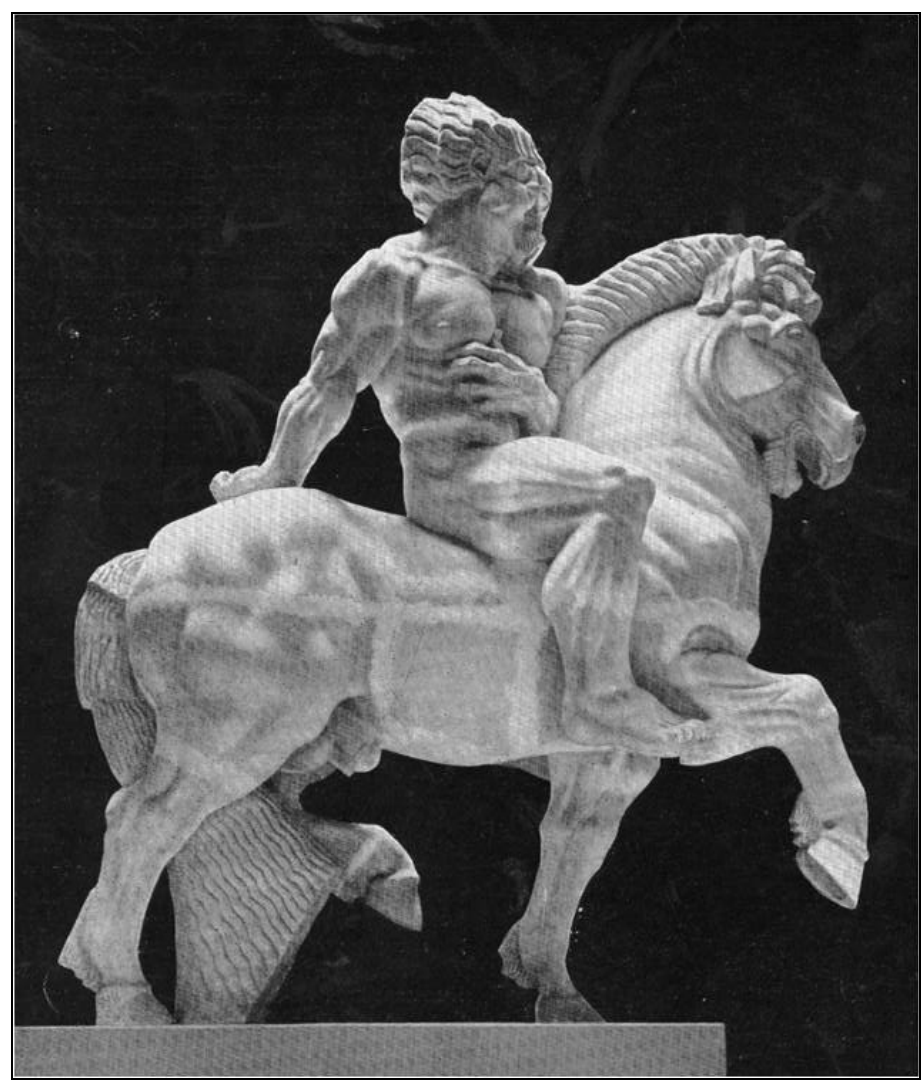

- Fig. 1. Iván Mestrovic. Marko Kraljevic. 1910.

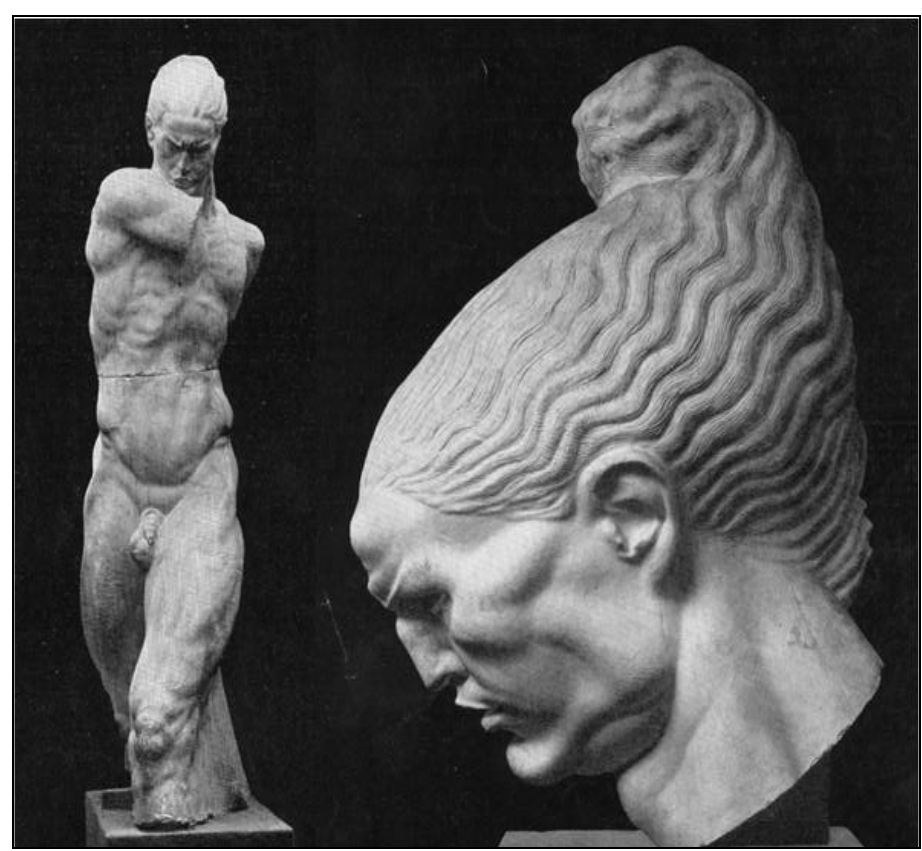

- Fig. 2. Iván Mestrovic. Milos Obilic. / Cabeza del héroe. 1909. 


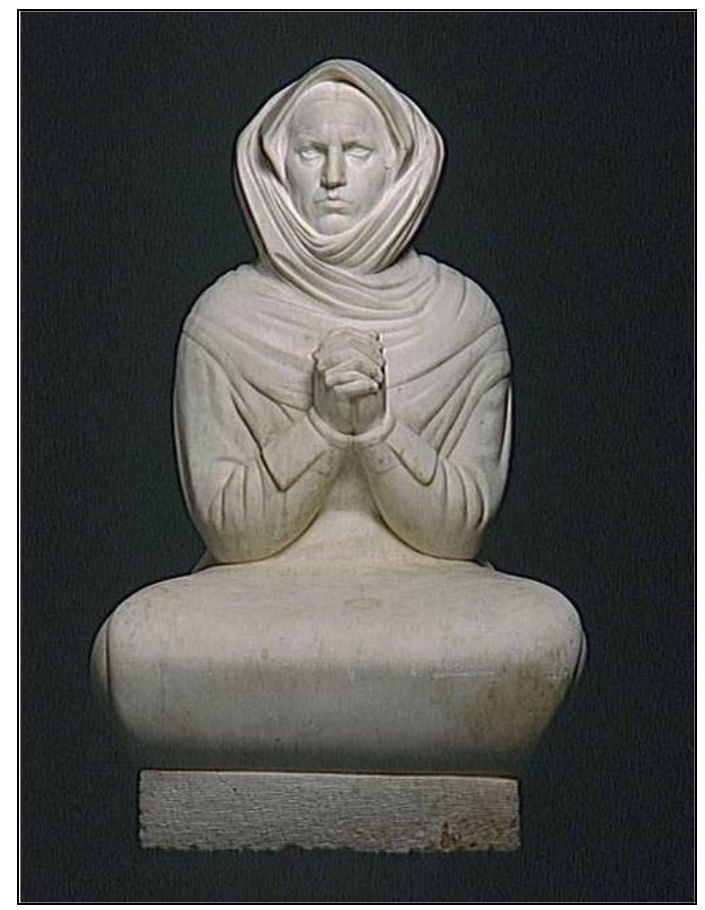

- Fig. 3. Iván Mestrovic. La madre del escultor. 1908.

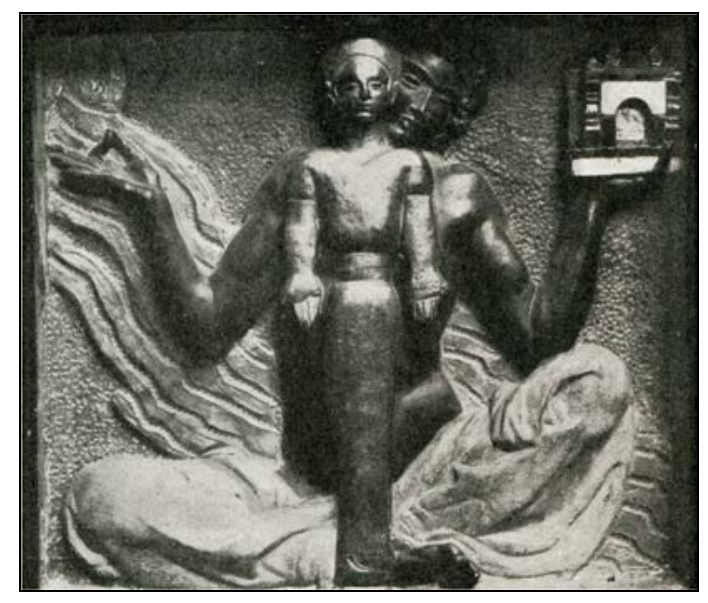

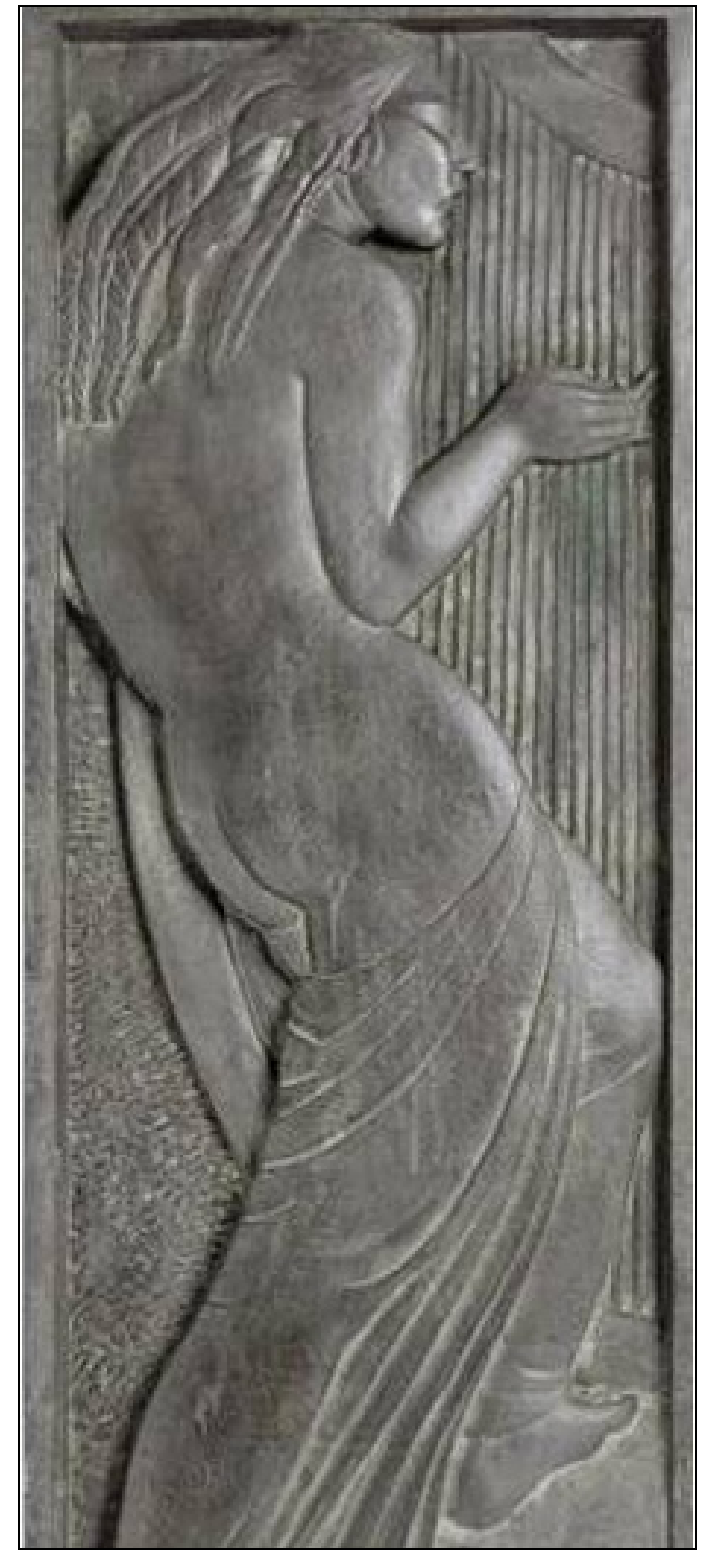

- Fig. 4. Iván Mestrovic. Mujer del arpa.

- Fig. 5. José Capuz. El ídolo. Exposición Nacional de Bellas Artes de 1922. 


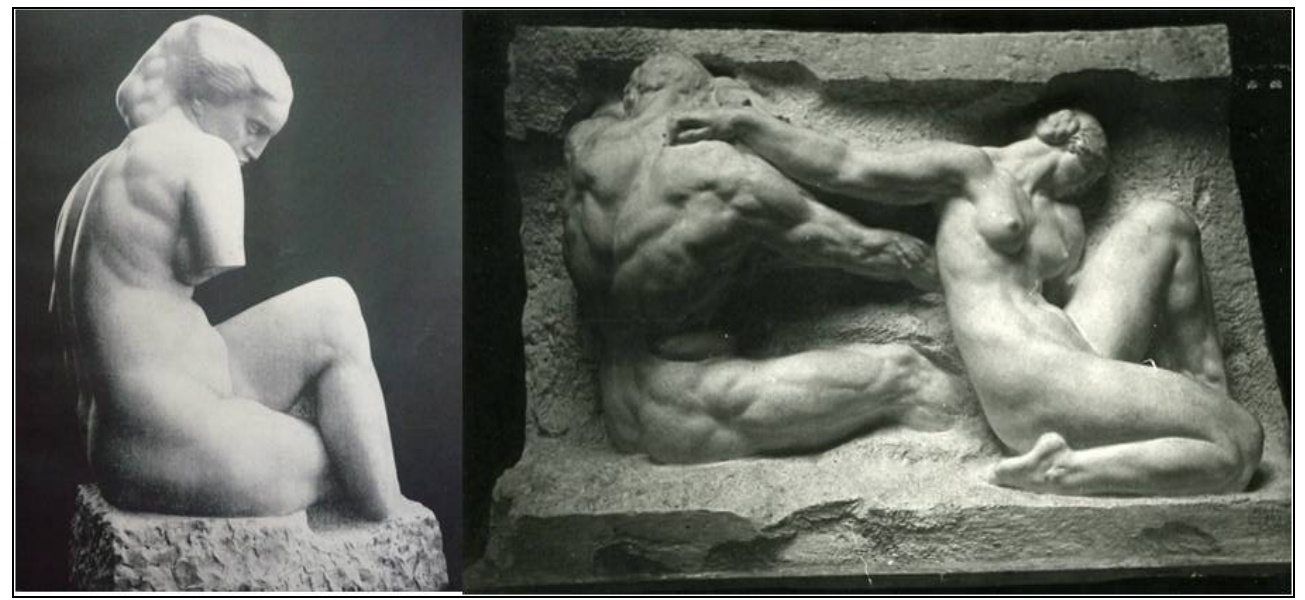

- Fig. 6. Iván Mestrovic. Recuerdo. 1910. / Moisés de Huerta. Naturaleza. Roma, 1911.

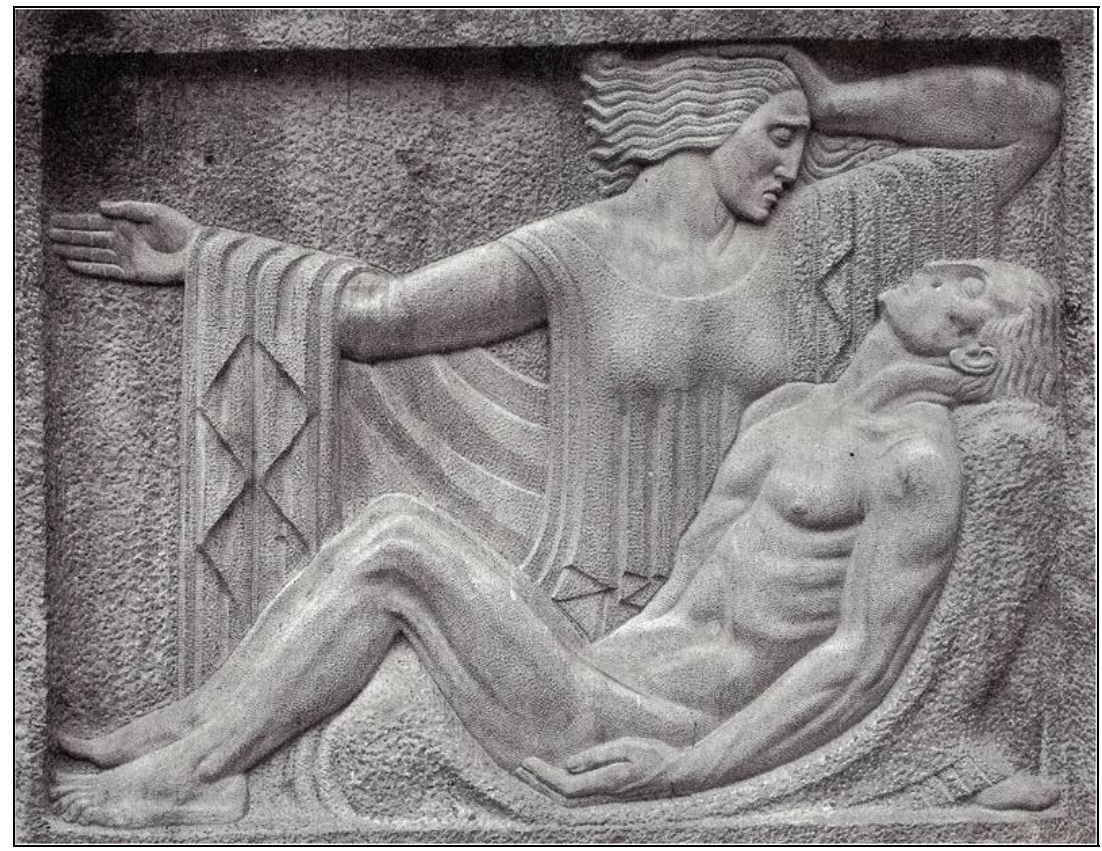

- Fig. 7. Victorio Macho. Fons Mortis. Relieve de la Fuente de Ramón y Cajal. 1922. 

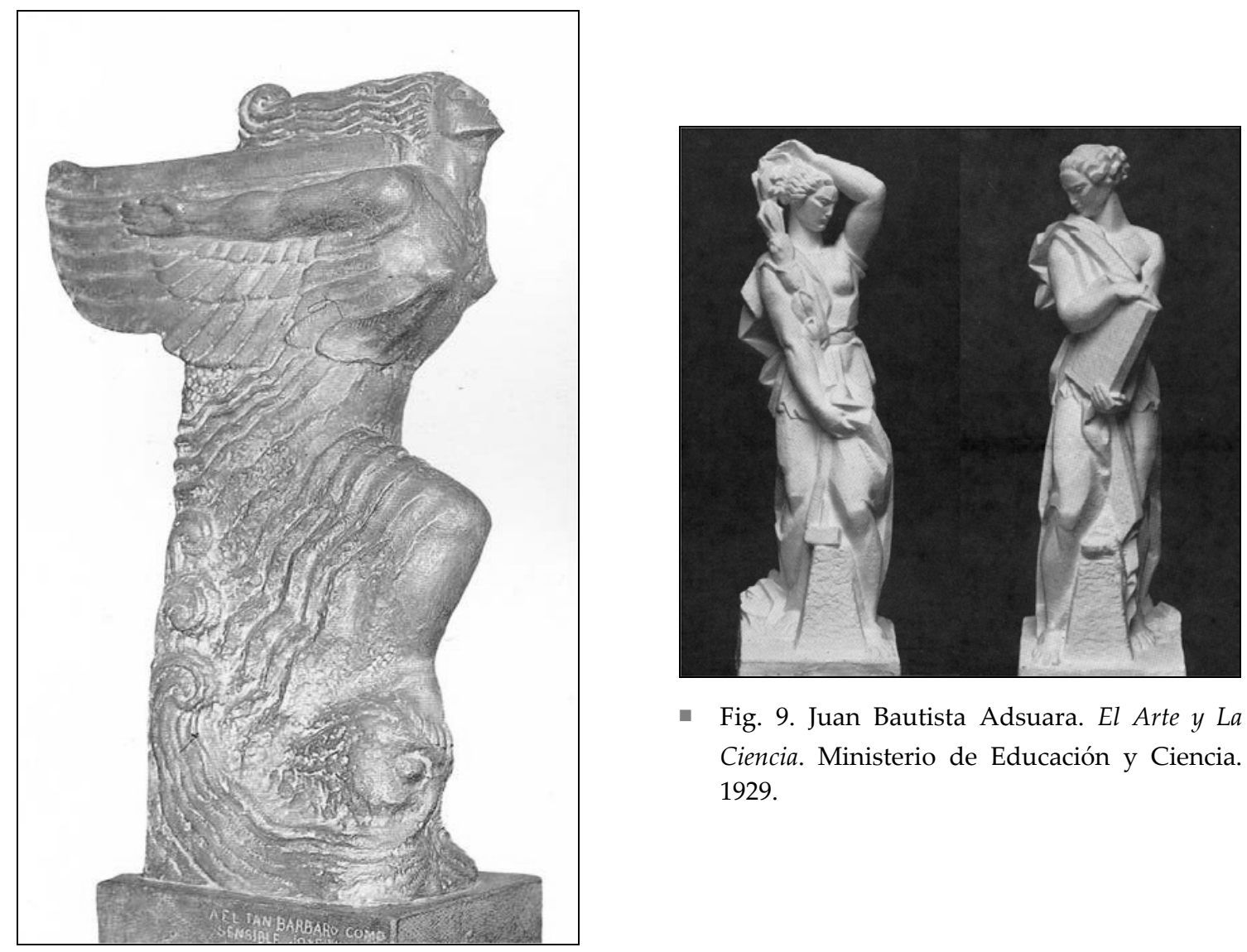

- Fig. 9. Juan Bautista Adsuara. El Arte y La Ciencia. Ministerio de Educación y Ciencia. 1929.

- Fig. 8. Victorio Macho. Versión de La Victoria del Monumento a Elcano. 1925.

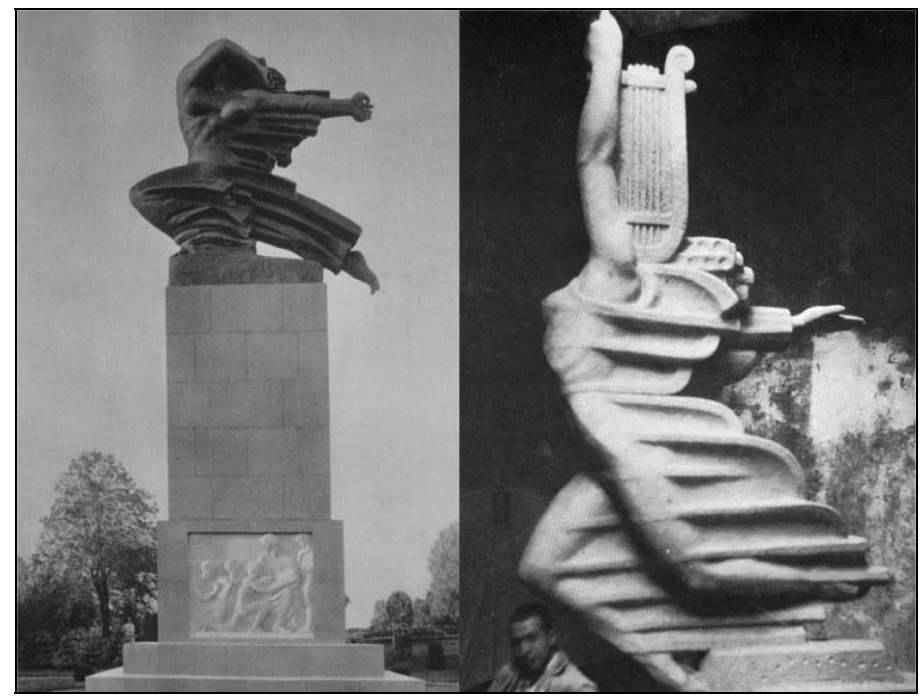

- Fig. 10. Iván Mestrovic. Monumento de gratitud a Francia. 1930. / Joaquín Lucarini. Victoria de la Música. 1932. 


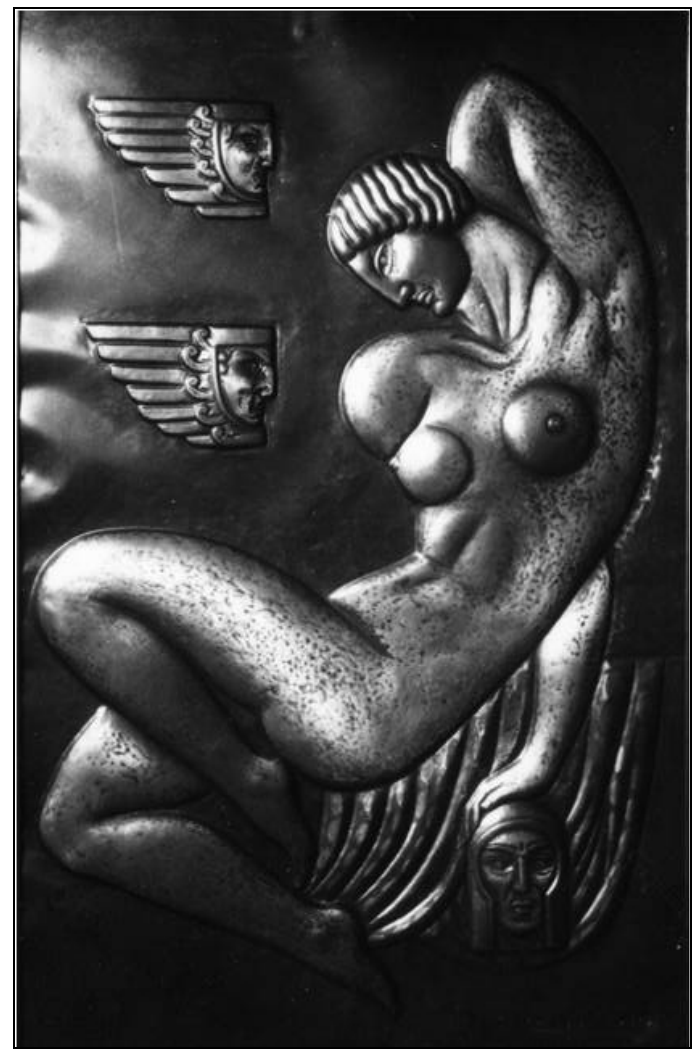

- Fig. 11. Eulogio Blasco. Fantasía. 1915-1925.

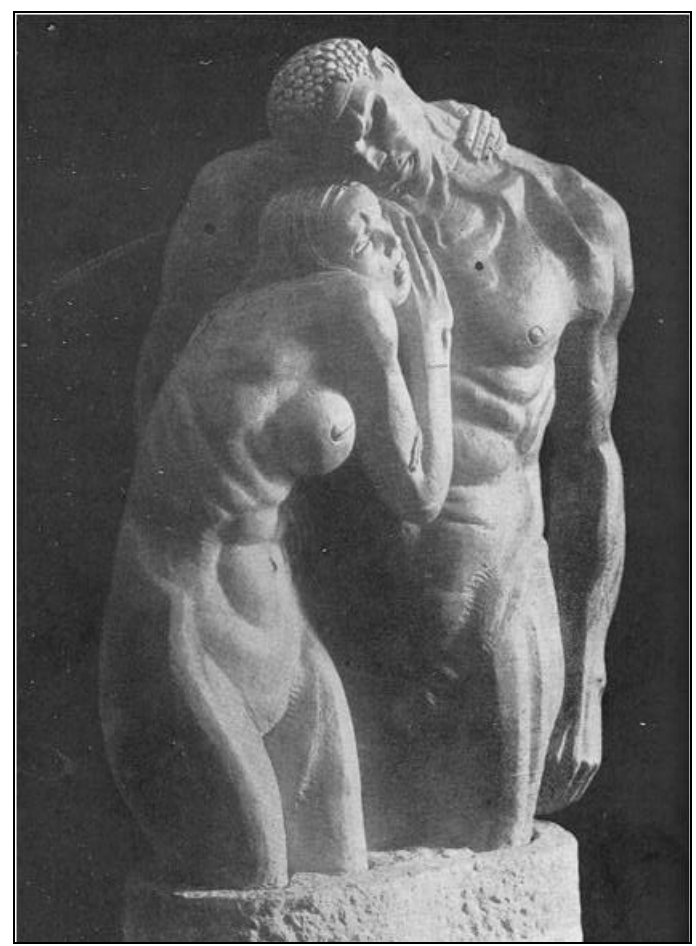

- Fig. 12. Marga Gil Röesset. Adán y Eva. 1930. 